University of Nebraska - Lincoln

DigitalCommons@University of Nebraska - Lincoln

January 2006

\title{
REGIONAL SEISMIC SONG DIFFERENCES IN SKY ISLAND POPULATIONS OF THE JUMPING SPIDER HABRONATTUS PUGILLIS GRISWOLD (ARANEAE, SALTICIDAE)
}

\author{
Damian O. Elias \\ University of Toronto at Scarborough, Ontario \\ Eileen Hebets \\ University of Nebraska - Lincoln, ehebets2@unl.edu \\ Ronald R. Hoy \\ Cornell University, Ithaca, New York \\ Wayne P. Maddison \\ University of British Columbia, Vancouver, British Columbia, V6T 1Z4, Canada \\ Andrew C. Mason \\ University of Toronto at Scarborough, Ontario, Canada
}

Follow this and additional works at: https://digitalcommons.unl.edu/bioscihebets

Part of the Behavior and Ethology Commons

\begin{abstract}
Elias, Damian O.; Hebets, Eileen; Hoy, Ronald R.; Maddison, Wayne P.; and Mason, Andrew C., "REGIONAL SEISMIC SONG DIFFERENCES IN SKY ISLAND POPULATIONS OF THE JUMPING SPIDER HABRONATTUS PUGILLIS GRISWOLD (ARANEAE, SALTICIDAE)" (2006). Eileen Hebets Publications. 8.

https://digitalcommons.unl.edu/bioscihebets/8
\end{abstract}

This Article is brought to you for free and open access by the Papers in the Biological Sciences at DigitalCommons@University of Nebraska - Lincoln. It has been accepted for inclusion in Eileen Hebets Publications by an authorized administrator of DigitalCommons@University of Nebraska - Lincoln. 


\title{
REGIONAL SEISMIC SONG DIFFERENCES IN SKY ISLAND POPULATIONS OF THE JUMPING SPIDER HABRONATTUS PUGILLIS GRISWOLD (ARANEAE, SALTICIDAE)
}

\author{
Damian O. Elias, ${ }^{1,2,5}$ Eileen A. Hebets, ${ }^{3}$ Ronald R. Hoy, ${ }^{4}$ Wayne P. Maddison ${ }^{2}$ and \\ Andrew C. Mason ${ }^{1}$ : $\quad{ }^{1}$ Division of Life Sciences, Integrative Behaviour and \\ Neuroscience, University of Toronto at Scarborough, 1265 Military Trail, \\ Scarborough, Ontario, M1C 1A4, Canada; ${ }^{2}$ Departments of Zoology and Botany, \\ University of British Columbia, Vancouver, British Columbia, V6T 1Z4, Canada; \\ ${ }^{3}$ School of Biological Sciences, University of Nebraska, Lincoln, Nebraska 68588, \\ USA; ${ }^{4}$ Department of Neurobiology and Behavior, Cornell University, Ithaca, New \\ York 14850, USA.
}

\begin{abstract}
Jumping spiders have long been used as model organisms to study visual communication. However, recent studies documenting the presence of intricate multicomponent seismic songs during courtship displays suggest an important role of seismic communication as well. Given the relatively recent focus on seismic communication, the extent to which seismic songs vary among jumping spider species or even among populations remains poorly understood. Here, we use the extensively studied Habronattus pugillis Griswold 1987 complex to explore putative seismic song diversity among males from isolated populations. H. pugillis populations have been studied extensively because of the tremendous diversification of male visual secondary sexual ornaments observed among adjacent mountain-top populations in southeastern Arizona ("sky islands"). Here, we aim to explore putative parallel patterns of diversification in seismic courtship songs between different sky island populations. Using laser vibrometry, we examined in detail the songs of three mountaintop populations (Atascosa (AT), Santa Rita (SR), and Santa Catalina (SC)) and observed an extraordinary diversity of songs and song types among these three populations. Large differences were seen in both the temporal and spectral properties of male seismic songs. In addition, we observed differences in song complexity between populations with some populations having "simple" songs ( 1 component) and others having "complex" songs ( 3 components). We also present preliminary data from four additional populations (Galiuro (GA), Huachuca (HU), Mule (MU), and Patagonia (PA)). Results from this study suggest that the diversification of male visual signals observed among populations of $H$. pugillis finds a counterpart in male seismic songs
\end{abstract}

Keywords: Seismic communication, signal evolution, species diversification, Salticidae

Jumping spiders have proven to be fruitful models in the study of ecology, behavior, and evolution, particularly as it relates to visually guided behaviors (Land 1969a, 1969b, 1985; Eakin \& Brandenburger 1971; DeVoe 1975; Williams \& McIntyre 1980; Blest et al. 1981; Land \& Nilsson 2002). Studies have demonstrated the amazing visual abilities that jumping spiders possess by focusing on behaviors from a variety of contexts including predatory, navigational, mating, and competitive interactions (Crane 1949; Jackson 1977; Hill 1979;

${ }^{5}$ Corresponding author. E-mail: elias@utsc. utoronto.ca
Forster 1982a,1982b; Richman 1982; Clark \& Uetz 1990, 1992, 1993; Tarsitano \& Jackson 1992, 1994, 1997; Edwards \& Jackson 1994; Jackson \& Pollard 1996; Harland et al. 1999; Harland \& Jackson 2000, 2001, 2002; Nakamura \& Yamashita 2000; Taylor et al. 2000, 2001; Clark \& Morjan 2001; Jackson et al. 2005; Li \& Lim 2005; Nelson et al. 2005; Hoefler \& Jakob 2006; Nelson \& Jackson 2006; Su \& Li 2006). However, recent research has highlighted the utilization of seismic (vibratory) songs during courtship displays (Jackson 1977, 1982; Edwards 1981; Gwynne \& Dadour 1985; Maddison \& Stratton 1988a, 1988b; Noordam 2002; Elias et al. 
2003) and a few studies have demonstrated that these seismic songs are crucial for mating success (Elias et al. 2004, 2005, 2006a). Despite the recent increase in studies focused on seismic communication in jumping spiders, we still know very little about the taxonomic breadth and/or importance of this mode of communication within the family Salticidae.

Jumping spiders in the genus Habronattus have been the subject of extensive studies focused on species diversification, phylogeography, communication, mate choice, signal design, and sexual selection (Griswold 1987; Cutler 1988; Maddison \& Stratton 1988a, 1988b; Masta 2000; Maddison \& McMahon 2000; Masta \& Maddison 2002; Elias et al. 2003, 2004, 2005, 2006a, 2006b; Maddison \& Hedin 2003; Hebets \& Maddison 2005). Not only is this genus diverse, with over 100 species described in North America (Griswold 1987; Maddison \& Hedin 2003), but it also incorporates extensive morphological and behavioral differentiation among its many species. Habronattus males include some of the most elaborate male ornamentation and visual courtship behaviors known among any spider species (Peckham \& Peckham 1889, 1890; Griswold 1987; Maddison \& Hedin 2003). In addition to their elaborate ornamentation, it was recently demonstrated that some species of Habronattus produce complex multicomponent seismic songs (vibrations) simultaneous with visual signals during courtship (Maddison \& Stratton 1988b; Elias et al. 2003, 2005, 2006a). Furthermore, these seismic signals were shown to be a crucial factor in mating decisions (Elias et al. 2004, 2005).

One particularly well studied group of $\mathrm{Ha}$ bronattus are those in the $H$. pugillis complex. In North America, populations of $H$. pugillis Griswold 1987 occur in woodland habitats isolated at the top of mountain ranges in southeastern Arizona and into Mexico. These mountain ranges are known as "sky islands" because their peaks form an archipelago of isolated woodlands separated by desert lowlands (Warshall 1995). Males from these various isolated populations are exceptional in that each possesses distinct secondary sexual traits involving both morphological and behavioral differences (Maddison \& McMahon 2000; Elias et al. 2006b). While there is an impressive among-population variation in $H$. pugillis males, within a population or moun- tain range, males are very similar (Maddison $\&$ McMahon 2000). Using a combination of behavioral, molecular, and phylogenetic data, Masta \& Maddison (2002) demonstrated that sexual selection was driving the observed diversification of male traits. Hebets \& Maddison (2005) then suggested that a process of antagonistic co-evolution (Holland \& Rice 1998) could be responsible for driving amongpopulation variation in female mating preferences and associated male traits. In a reciprocal mate choice study, they found a xenophilic mating preference in which $H$. pugillis females from the Santa Rita Mountains preferred males from a foreign population, from the Atascosa Mountains, over their own local males (Hebets \& Maddison 2005). Male $H$. pugillis from the Atascosa (AT) and Santa Rita (SR) populations were also recently observed to produce complex seismic songs (Elias et al. 2005, 2006a). In a follow-up study exploring the previously established SR female preference for AT males (Hebets \& Maddison 2005), Elias et al. (2006a) demonstrated that a female bias for complex/novel seismic signals was responsible for the observed xenophilic preference and suggested that a general bias for complexity/novelty among females could have contributed to the rapid diversification observed in the $H$. pugillis group (Masta 2000; Masta \& Maddison 2002).

The goal of this particular study was to document and compare seismic courtship songs of $H$. pugillis populations. In so doing, we demonstrate that the striking diversity of visual displays observed among populations of H. pugillis finds a counterpart in seismic songs among populations. We detected differences in both the temporal and spectral properties of songs between populations. In addition, we observed differences in the complexity of songs, with some populations having songs with a single component and others having multiple components. This is the first study to our knowledge to show regional differences in spider songs. We suggest that seismic songs along with visual ornaments are under strong selection in $H$. pugillis and we discuss the evolutionary forces that may have driven this diversification of seismic songs. 


\section{METHODS}

Spiders.-Male and female H. pugillis were collected from different mountain ranges in Arizona (Atascosas (AT) $31^{\circ} 24.63^{\prime} \mathrm{N}, 111^{\circ} 8.77^{\prime} \mathrm{W}$; Santa Ritas (SR) $31^{\circ} 40.38^{\prime} \mathrm{N}, 110^{\circ} 52.82^{\prime} \mathrm{W}$; Santa Catalinas (SC), 32 $21.40^{\prime} \mathrm{N}, 110^{\circ} 55.37^{\prime} \mathrm{W}$; Galiuros (GA), $32^{\circ} 34.58^{\prime} \mathrm{N}, 110^{\circ} 16.50^{\prime} \mathrm{W}$; Huachucas (HU) $31^{\circ} 25.94^{\prime} \mathrm{N}, 110^{\circ} 17.50^{\prime} \mathrm{W}$; Patagonias (PA) $31^{\circ} 23.87^{\prime} \mathrm{N}, 110^{\circ} 44.44^{\prime} \mathrm{W}$, and Mules (MU) $31^{\circ} 29.68^{\prime} \mathrm{N}, 109^{\circ} 59.82^{\prime} \mathrm{W}$ ) over three field seasons (April-June 2002, AprilMay 2003, April-May 2004). Males and females were collected as immatures and adults. Male courtship songs were recorded up to a maximum of 3 mo after the animals were collected. As males senesce, they cease to initiate courtship and instead avoid or act aggressive towards females (Elias, pers. obs.), thus only males that actively courted females were used. Animals were housed individually in plastic containers (AMAC Plastic Products, Petaluma, $\mathrm{CA} ; 3 \times 3 \times 5 \mathrm{~cm})$ and kept segregated by sex. Animals were kept in the lab on a 12:12 light: dark cycle. Spiders were fed fruit flies (Drosophila melanogaster) and juvenile crickets (Acheta domesticus) once a week. Male voucher specimens are deposited at the Royal Ontario Museum, Toronto, Canada.

Recording procedures and analysis.Detailed measurements on seismic songs were made using laser vibrometry (Elias et al. 2003). We first anesthetized a mature female H. pugillis with $\mathrm{CO}_{2}$ and tethered her to a wire with low melting point wax (beeswax). We held females in place with a micromanipulator on a substrate of nylon fabric $(25 \times 30 \mathrm{~cm})$ stretched across a needlepoint frame to standardize the tension of the nylon. As courting substrate has significant effects on signal transmission (Magal et al. 2000; Cokl et al. 2004, 2005; Elias et al. 2004), we used the nylon fabric as our courting surface since it has negligible resonance characteristics and passes all frequencies equally (Elias et al. 2003, 2006c), thus enabling us to observe all the potential temporal and frequency components of a male's song. Mature males were dropped individually onto this substrate $15 \mathrm{~cm}$ from the female and allowed to court freely. Recordings began when males orientated towards females. Fifteen different females were used to initiate courtship from thirty-nine mature males. Males were collected as matures and thus we have no data on male age. We recorded seismic vibrations using a laser doppler vibrometer (LDV) (Polytec OFV 3001 controller, OFV 511 sensor head) (Michelsen et al. 1982). Pieces of reflective tape (approx. $1 \mathrm{~mm}^{2}$ ) were attached to the underside of the courtship substrate $2 \mathrm{~mm}$ from the female to serve as measurement points for the LDV. The LDV signal was recorded on the audio track during standard video taping of courtship behavior (Sony DVCAM DSR-20 digital VCR, $48 \mathrm{kHz}$ audio sampling rate). Spectrograms were made using Raven software (Cornell University, Lab of Ornithology). We present detailed measurements of spider songs of three populations (AT, $n=15$; SR, $n=12$; $\mathrm{SC}, n=12)$. Means are given $\pm \mathrm{SD}$.

As it was not possible to record songs for all the populations using LDV, we present preliminary data on songs from four more populations (GA, $n=10$; PA, $n=5$; MU, $n=$ 3 ; HU, $n=3$ ) that we recorded using a custom piezoelectric sensor built from a turntable needle cartridge. For this recording technique, the courtship arena was a sheet of graph paper attached to a square cardboard frame $(60 \times$ $45 \mathrm{~cm}$ ). Females were tethered as above and the male's seismic signals were recorded using a piezo-electric sensor placed directly underneath the tethered female. Ten different females were used in piezo-electric recordings. In comparing populations where we recorded a male's signal using both LDV and the piezoelectric sensor, we observed that although low frequency responses $(<150 \mathrm{~Hz})$ were relatively attenuated by the piezoelectric sensor, the male's signals were not significantly altered and all signal components were apparent albeit at lower amplitude (Elias et al. 2003). All piezo recordings were conducted in a soundattenuated chamber at Cornell University. Seismic signals were amplified (Nikko NA790), recorded on the audio track of a video recording as above $(48 \mathrm{kHz}$ audio sampling rate) and high-pass filtered $(>150 \mathrm{~Hz})$. We present examples of typical spider songs from the recordings available.

As all recordings were conducted with tethered females, it is possible that males behave differently under these conditions than they would in the field. These differences however appear to be more in the duration of courtship displays and not in the individual song components. For example, in situations where fe- 
males were not tethered, males courted for longer durations overall, but used the same song components (Elias, pers. obs.). In addition, since males were collected as matures, they may have previously mated in the field. Here, also, we suggest that previous experience is unlikely to alter the specific components of seismic signal production but, instead, alters more plastic behaviors such as courtship duration or latency to court.

\section{RESULTS}

Visual courtship signals in $H$. pugillis.The visual courtship behavior of $H$. pugillis varies by population, but in general courtship can be divided into two main stages: (1) the approach stage and (2) the pre-mount stage (Maddison \& McMahon 2000). In the approach stage, the male raises and spreads his first pair of legs and lowers and spreads his palps. The male then proceeds to approach the female either directly or in a sidling motion while flicking (rapidly moving) his forelegs and pedipalps in a stereotyped manner. When the male gets within one to two body lengths of the female, the pre-mount stage begins (Maddison \& McMahon 2000). In the premount stage, the male's approach slows down, and leg and pedipalp flicking becomes more rapid-especially downward flicks of the first pair of legs. Males also scrape the abdomen repeatedly against the carapace just prior to mounting a female. It was suggested by Maddison \& McMahon (2000) that this grinding corresponded to the production of seismic songs.

Seismic songs in $\boldsymbol{H}$. pugillis.-Seismic songs are, in fact, produced by $H$. pugillis males at the moment the abdomen is seen to rub against the carapace. Preventing the abdomen from moving relative to the carapace prevents song production (Elias et al. 2006a). Song production varies from population to population and males can produce songs in the approach stage and/or the pre-mount stage. Song production is usually coordinated with flicking of forelegs. The general $H$. pugillis song can have three components. The first component (A) ("crackle") is generally of short duration, broad frequency and relatively high intensity; crackles have an impulse-like quality. The crackle component is generally the first song component produced and is present in all observed populations of $H$. pugillis.
Some populations only include the crackle component (see below) and these tend to have crackles that are longer in duration than populations with additional components. The second component (B) ("rasp") is generally long in duration and broad in frequency. Rasps occur in all populations immediately prior to an attempted mount but, in some populations, from long distances. The third component $(\mathrm{C})$ ("drone") is short in duration and broad in frequency but occurs at lower frequencies than crackles. Drones occur in bouts consisting of multiple signals produced rapidly following each other.

All $H$. pugillis songs are composed of similar song components, but there is variation in (1) the types and number of components and (2) the temporal and spectral characteristics of the different components. Below are detailed descriptions of male songs of three different sky island populations followed by preliminary descriptions of four additional populations.

Courtship behavior of $\boldsymbol{H}$. pugillis.-Santa Rita (SR) males: The courtship behavior of SR males begins with rotations of the palps (Maddison \& McMahon 2000). This palpal rotation is unique to SR males and is continued throughout the courtship display. Palpal rotations are often punctuated with rapid leg flicks. Males remain mostly stationary during courtship until the actual approach to the female, which is generally direct rather than sidling. The final stages of courtship involve the male holding his first pair of legs above the female and flicking the tips. Leg flicking occurs less often than in other populations (i.e., AT, SC, PA, HU). Leg flicks are coordinated with seismic songs (Fig. 1) which consist of a single component. SR seismic songs are of variable duration but are generally short $(0.56$ $\pm 0.393 \mathrm{~s} ; n=17$ ) and consist of high intensity, broad band (range: 0-2850 Hz; peak frequency: $1082 \pm 540 \mathrm{~Hz} ; n=17)$ crackles (labelled "a" in Fig. 1). Some SR males include rasps at extremely short ranges just prior to attempted copulation (Fig. 1, 48-55 s, SR column). The majority of seismic signals however only include the crackle component (Fig. 1).

Santa Catalina (SC) males: SC courtship begins with rapid foreleg flicks followed by body shakes (rapid side-to-side movements) during the approach stage of courtship (Mad- 

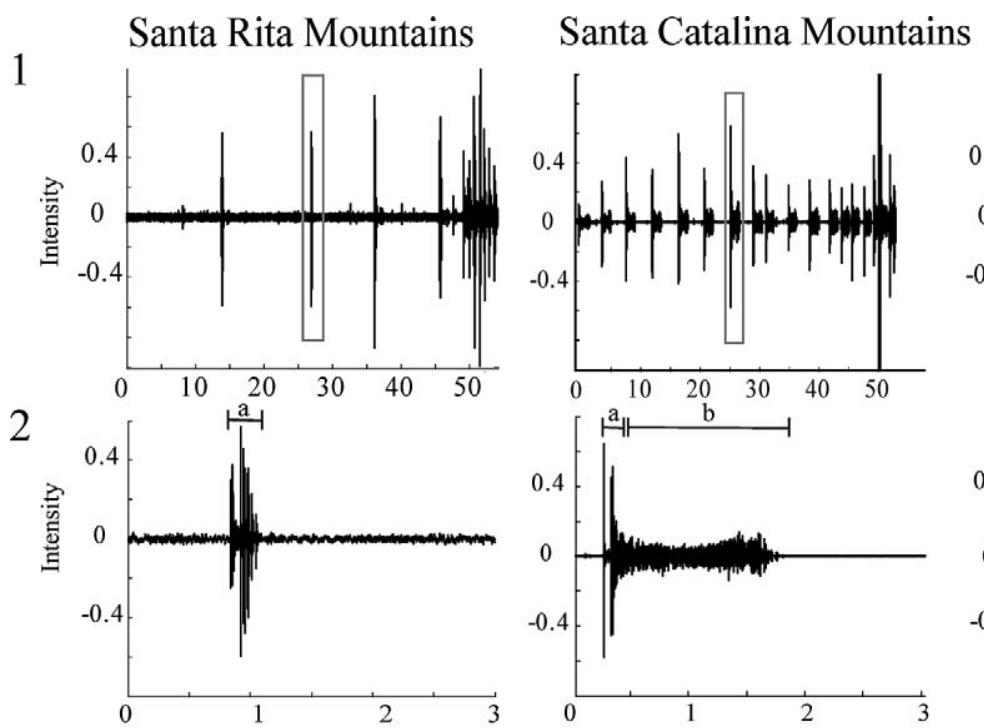

Atascosa Mountains
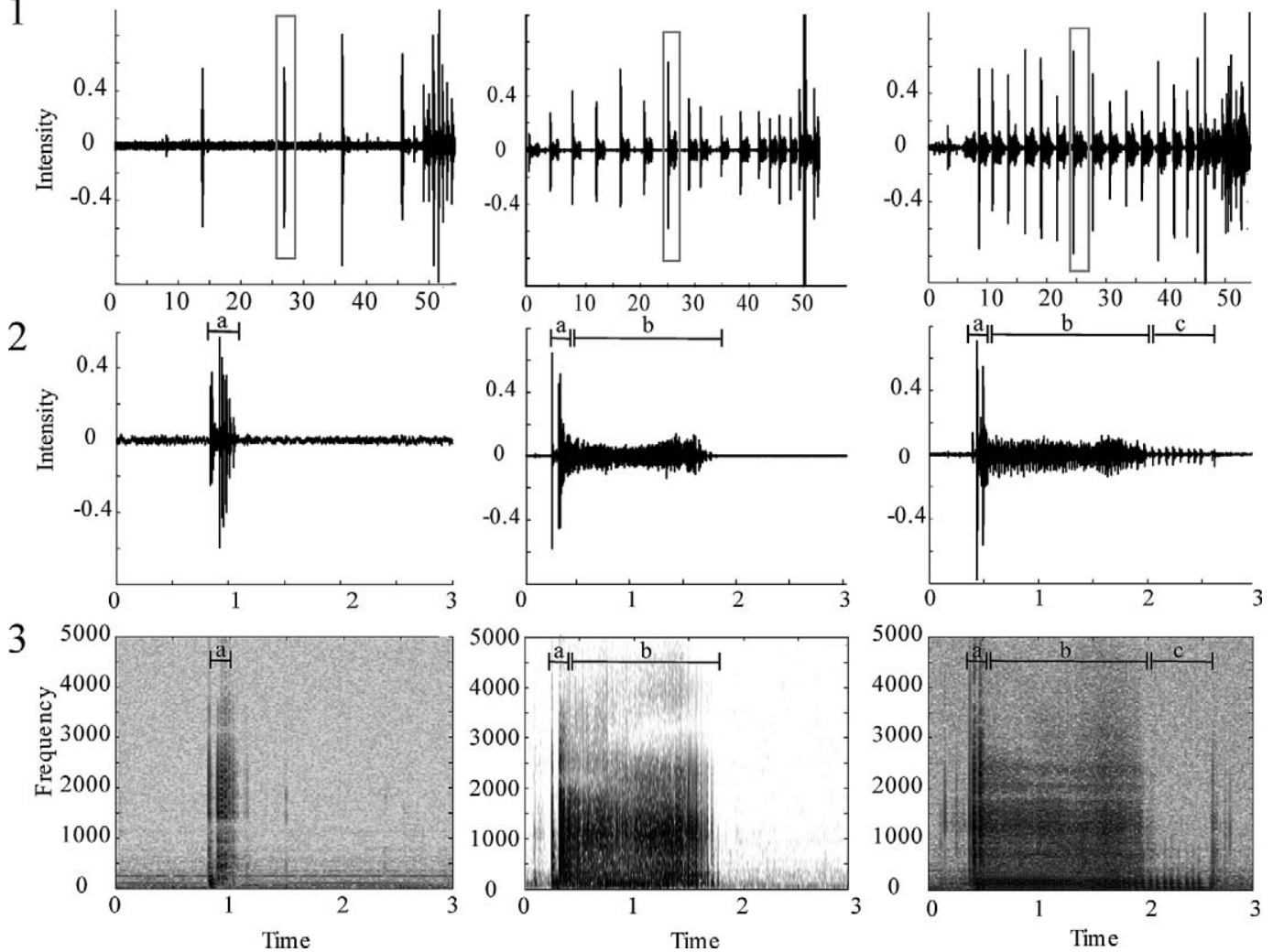

Figures 1-3.- Habronattus pugillis song from the Santa Rita, Santa Catalina and Atascosa mountain populations. 1. Oscillograms of seismic songs. 2. Detail of oscillograms (boxes in Fig. 1). 3. Spectrogram of song in Fig. 2. The notation a-c in Figs. $2 \& 3$ identifies the three seismic components of male songs.

dison \& McMahon 2000). After body shaking, males approach females with vigorous foreleg flicking. Seismic signals are produced during leg flicks preceding body shakes as well as during late display leg flicks. Seismic signals are not produced during a body shake bout but occur immediately after body shaking ends. Every foreleg flick is coordinated with a seismic signal (Fig. 2). SC male seismic songs are long in duration $(1.30 \pm 0.20 \mathrm{~s} ; n=15)$ and occur in two distinct parts (Fig. 2). The first part consists of a short $(0.13 \pm 0.16 \mathrm{~s} ; n=$ 15), high intensity, broad band (range: 0-3937 Hz; peak frequency: $844 \pm 349 \mathrm{~Hz} ; n=15$ ) "crackle" (labelled "a" in Fig. 2). The second part consists of a prolonged long duration (1.17 $\pm 0.19 \mathrm{~s} ; n=15)$ broadband "rasp" (range 1: 7-1211 Hz; peak 1 frequency: 185 $\pm 198 \mathrm{~Hz}$; range 2: 900-2500 Hz; peak 2 frequency: $1373 \pm 317 \mathrm{~Hz} ; n=15$ ) (labelled "b" in Fig. 2).
Atascosa (AT) males: AT locomotory courtship consists of rapid sidling, in which males move in large arcs alternating in direction with the first pair of legs held continuously above the ground (Maddison \& McMahon 2000). After sidling, males approach females with vigorous foreleg flicking. Seismic signals are produced during leg flicking and not during the sidling display. Every leg flick is coordinated with a seismic signal (Fig. 3). AT male seismic songs are long in duration (1.85 $\pm 0.30 \mathrm{~s} ; n=15)$ and occur in three distinct parts (Fig. 3). The first part consists of a short $(0.11 \pm 0.03 \mathrm{~s} ; n=15)$, high intensity, broad band (range: 0-2640 Hz; peak frequency: $1069 \pm 339 \mathrm{~Hz} ; n=15)$ "crackle" (labelled "a" in Fig. 3). The second part consists of a prolonged $(1.07 \pm 0.34 \mathrm{~s} ; n=15)$ broadband "rasp" (range 1: 0-650 Hz; peak 1 frequency: $203 \pm 218 \mathrm{~Hz}$; range 2: 530-2010 Hz; peak 2 frequency: $1170 \pm 210 \mathrm{~Hz} ; n=15$ ) ("b" 
in Fig. 3). The third part consists of a variable number of "drones" (3-9; $n=5)$ of short duration $(0.04 \pm 0.01 \mathrm{~s} ; n=18)$ broad band (range: 0-1850 Hz; peak frequency $371 \pm$ $457 \mathrm{~Hz} ; n=18$ ) signals ("c" in Fig. 3). Broad band drones also occur along with rasps in the second courtship stage ("b" in Fig. 3) but are lower in intensity than rasps.

Other H. pugillis males: We observed the seismic songs of four additional populations, Galiuro (GA), Huachuca (HU), Patagonia (PA), and Mule (MU) mountains (Fig. 4). Detailed measurements were not available for these populations and we were only able to record songs using the piezoelectric device (see above). It is possible that we were not able to observe all song components using this method of sound recording therefore, future recordings will be conducted using LDV.

Galiuro (GA) visual courtship consists of a "first leg wavy circle" where the first legs are held forward and the tips moved in circles simultaneously (but out of phase) (Maddison \& McMahon 2000). Periodically the first legs come into phase (sometimes punctuated with a rapid leg flick). Seismic songs are produced coincident with the first legs coming into phase (with and without leg flicks). Seismic songs in the GA population are made of crackles (a) and "slow" crackles (s-a) (Fig. 4). Slow crackles appear to consist of a series of crackles. Slow crackles have an impulselike punctuated quality like crackles and are different from rasps as rasps are produced as a continuous signal.

Huachuca (HU), Mule (MU), and Patagonia (PA) male courtship songs are similar to SC male courtship with the notable absence of body shakes. HU, MU, and PA males approach females with flicking of the first pair of legs. Seismic songs are produced during leg flicks. HU, MU, and PA male seismic songs occur in two distinct parts, crackles ("a," Fig. 4) and rasps ("b," Fig. 4). In the early stages of courtship, HU males also add a unique component to their display. HU males approach females slowly with the forelegs held above the ground the entire time. Periodically males open and close their chelicerae during this approach. Seismic signals are produced intermittently as the male slowly approaches the female. Seismic signals during this portion of the display consist of crackle components and are not coordinated with any movement of the forelegs. This character is unique among all the populations studied (data not shown).

\section{DISCUSSION}

H. pugillis is undergoing diversification driven by sexual selection (Maddison \& McMahon 2000; Masta 2000; Masta \& Maddison 2002; Hebets \& Maddison 2005; Elias et al. 2006a). Evidence suggests that sexual selection acting on male secondary sexual characteristics has driven extensive morphological and behavioral divergence between populations on the sky islands of south eastern Arizona (Maddison \& McMahon 2000; Masta \& Maddison 2002). Here we show that the diversity observed previously was only a partial picture and is further manifested in the evolution of distinct and stereotyped songs among different populations.

$H$. pugillis songs consist of similar components, although some populations have more complex songs than others. Males from the Santa Rita Mountains have simple songs, consisting of a single component. Males of the other populations have more complex songs with males from the Santa Catalinas having songs consisting of two components, and males from the Atascosas having songs consisting of three components. In addition to these broad scale differences between populations, temporal and spectral components are different between each population. There also appears to be variation in the coordination of visual and seismic components of courtship. Signal evolution involving seismic signals is thus potentially occurring along three axes: (1) frequency and temporal characteristics, (2) song complexity, as measured by the number of seismic components and, (3) multimodal coordination. Diversification in $H$. pugillis has probably occurred on a small temporal and spatial scale suggesting that the song differences between populations are likely due to selection and not random effects (Maddison \& McMahon 2000; Masta 2000; Masta \& Maddison 2002). Below we discuss some of the hypotheses that may drive the observed diversity of songs.

Spectral and temporal properties in animal songs often relay information about mate quality and/or species identity, resulting in substantial selection on song properties (Andersson 1994; Bradbury \& Vehrencamp 1998; 


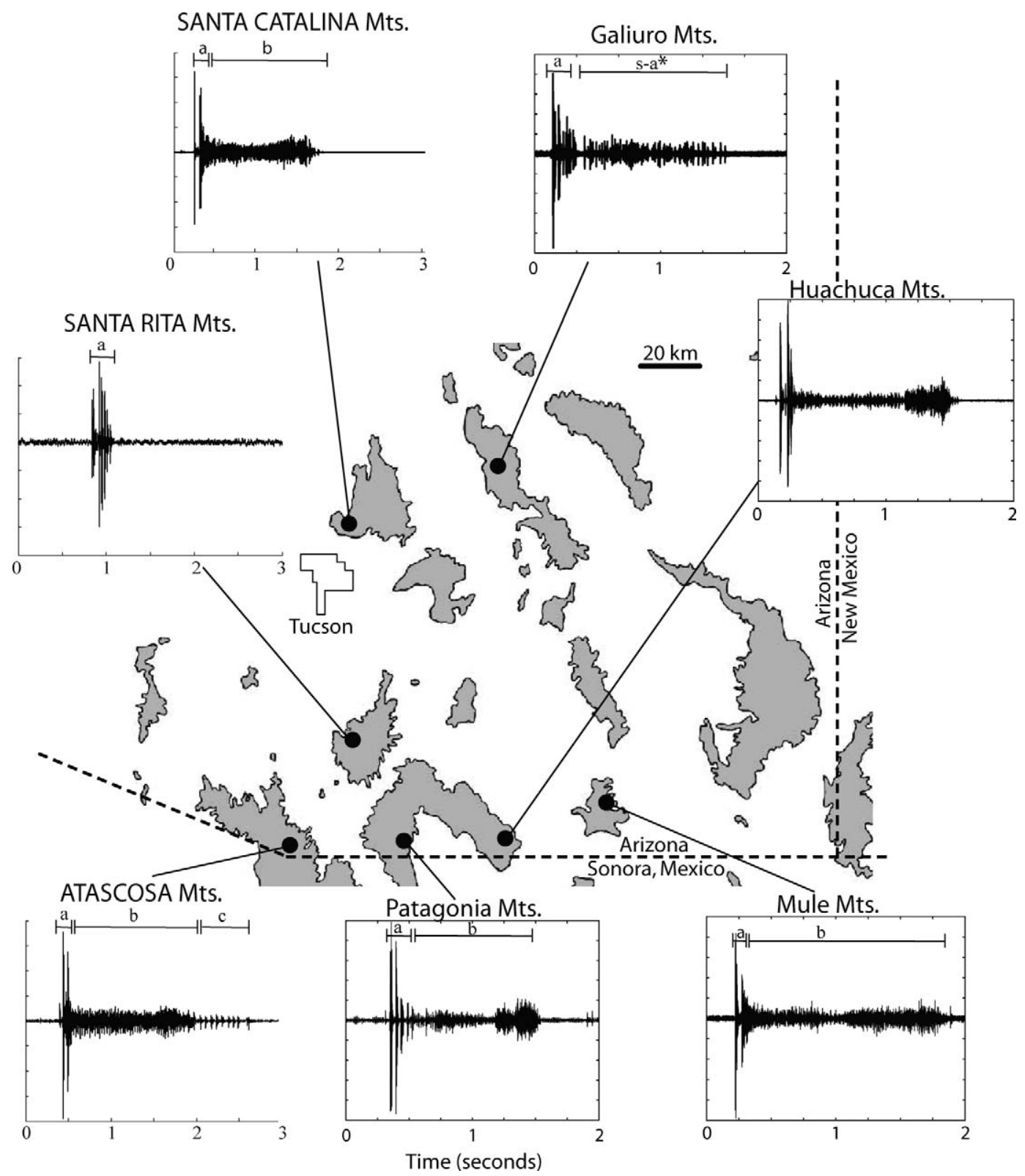

Figure 4.- Seismic song diversity in the sky islands of southern Arizona. Map of southern Arizona mountain ranges with outlines representing the lower limit of oak woodland habitat (Brown \& Lowe 1982), corresponding to an elevation of $\sim 1300-1500 \mathrm{~m}$. Dots show collecting localities for H. pugillis. Representative songs are shown for populations recorded using laser vibrometry (all caps-Atascosa, Santa Rita, Santa Catalina Mts.) and a piezo-electric sensor (Galiuro, Mule, Patagonia, and Huachuca Mts.). $\mathrm{a}-\mathrm{c}$ denote the three possible seismic components of male songs. *s-a denotes a "slow crackle".

Kotiaho et al. 1998; Parri et al. 2002; Gerhardt \& Huber 2002). This may be the case in $\mathrm{Ha}$ bronattus songs as well (Elias et al. 2005). The characteristics of the signaling environment (e.g., leaves, sand) can also add substan- tial selective pressures on signal evolution and on the spectral and temporal characteristics of signals (Michelsen 1978; Larsen \& Michelsen 1983; Romer 1998; Magal et al. 2000; Elias et al. 2004; Cokl et al. 2005). For example, 
Elias et al. (2004) demonstrated that seismic songs in $H$. dossenus Griswold 1987 could propagate well on only a subset of available substrates, resulting in differential mating success for males across substrates. Elias et al. (2004) went on to suggest that evolution may lead to substrate specialization and a tuning of spectral and temporal signal characteristics to the particular signaling substrates available. Similar selective pressures may have lead to differences in the temporal and spectral properties of songs between different sky island populations.

There also appears to be variation in song complexity between sky island populations. Differences in song complexity among populations may be due to differences in the signaling environment between sky islands. Efficacy-based hypotheses of complex signal function such as the multiple sensory environments hypotheses (Candolin 2003; Hebets \& Papaj 2005) suggest that multiple signals evolve when there is variation in the signaling environment so that under some conditions some signal components can be transmitted effectively when other signal components are not. Under an efficacy backup hypothesis (Hebets \& Papaj 2005), one would predict the AT signaling environment to be the most variable, followed by the SC and the SR signaling environments. While this possibility remains to be explicitly tested, there are no obvious differences between sky island signaling environments (Masta \& Maddison 2002).

Differences in song complexity between populations may also be due to selection for signal content, such as the need to convey multiple differential messages (Moller \& Pomiankowski 1993; Johnstone 1996; for review of content-based hypotheses see Hebets \& Papaj 2005). H. pugillis females mate only once (Hebets, unpublished observations), therefore informative signals may be at a premium. Due to differential natural selection pressure across mountaintop populations, it is possible that males from different populations might need to convey different aspects of quality to local females, resulting in divergent complex displays. Variable population densities could also influence complex signaling evolution as increased population density could increase male competition for mates, potentially resulting in an increase in display complexity as males are forced to provide in- formation about multiple aspects of quality. The observed correlation between population density and signal complexity however is in the exact opposite direction, as our collection sites with the most spiders (SR) had the simplest seismic songs (Elias, Hebets \& Maddison, unpubl. data). Clearly, future studies focused specifically on testing these hypotheses are necessary.

A role of antagonistic coevolution has been suggested in the evolution of complex, divergent courtship displays of $H$. pugillis (Hebets \& Maddison 2005; Elias et al. 2006a). Under antagonistic coevolution models (Holland \& Rice 1998), females are expected to evolve resistance to exploitative male signals thus forcing males to elaborate signals that are beyond the current realm of the female's resistance. Following from this, females are predicted to prefer males with novel exploitative traits over males with local traits for which they have evolved resistance. Under this scenario, if differences in song complexity in $H$. pugillis are being driven by antagonistic coevolution, then we would predict the following: SR females should prefer AT and SC songs over their own male songs (SR); SC females should prefer AT songs over SR songs and their own male songs (SC); and AT females should not show any preference. Hebets \& Maddison (2005) have already demonstrated that SR females prefer AT males, and that AT females did not show any preferences between SR and AT males. In addition, Elias et al. (2006a) showed that SR females preferred AT males only if they could produce seismic signals. Results thus far are consistent with the hypothesis that differences in song complexity are being driven by antagonistic co-evolution.

If we include songs for which we only have preliminary data, there also appears to be variation between the coordination of visual and seismic signals. Some populations show no multimodal coordination in certain song components (HU population), while others show high degrees of coordination (AT, SC, MU populations). Coordinated signaling in multiple modalities can present animals with multiple advantages including reduced signaling costs (sender), reduced processing costs (receiver), and increased information content (Honey \& Hall 1989; Partan \& Marler 1999, 2005; Rowe 1999; Candolin 2003; Uetz \& 
Roberts 2002; Hebets \& Papaj 2005). Differences in the importance of coordination and/ or differences in the cross-modal interactions between visual and seismic signal could also lead to the differences observed between the different populations.

Although, we have only described a small proportion of $H$. pugillis songs, our results show an interesting parallel with regional song differences in birds (Krebs \& Kroodsma 1980). Examining other sky islands in the US and Northern Mexico will likely reveal an even greater diversity of songs and song types. Given the extraordinary diversity of songs observed in this and other studies (Jackson 1977; Edwards 1981; Gwynne \& Dadour 1985; Maddison \& Stratton 1988a, 1988b; Noordam 2002; Elias et al. 2003, 2005), we propose that jumping spiders are a good system to study the function and evolution of songs.

\section{ACKNOWLEDGEMENTS}

We would like to thank M.C.B. Andrade, N. Lee, M. Kasumovic, K. Gawera, and the Hoy, Mason, Andrade, and Hebets Lab Groups. Funding was provided by NSERC to ACM (238882 241419), NIH to RRH (N1DCR01 DC00103), and an NSF IRFP (0502239) to DOE.

\section{LITERATURE CITED}

Andersson, M. 1994. Sexual Selection. Princeton University Press, Princeton, New Jersey. 599 pp.

Blest, A.D., R.C. Hardie, P. McIntyre \& D.S. Williams. 1981. The spectral sensitivities of identified receptors and the function of retinal tiering in the principal eyes of a jumping spider. Journal of Comparative Physiology 145:227-239.

Bradbury, J.W. \& S.L. Vehrencamp. 1998. Principles of Animal Communication. Sinauer Associates, Sunderland, Massachusetts. 882 pp.

Brown, D.E. \& C.H. Lowe. 1982. Biotic Communities of the Southwest. U.S. Forest Service General Technical Report RM-78. Rocky Mountain Forest and Range Experimental Station, Fort Collins, Colorado.

Candolin, U. 2003. The use of multiple cues in mate choice. Biological Reviews 78:575-595.

Clark, D.L. \& C.L. Morjan. 2001. Attracting female attention: the evolution of dimorphic courtship displays in the jumping spider Maevia inclemens (Araneae: Salticidae). Proceedings of the Royal Society of London Series B-Biological Sciences 268:2461-2465.

Clark, D.L. \& G.W. Uetz. 1990. Video image recognition by the jumping spider, Maevia incle- mens (Araneae: Salticidae). Animal Behaviour 40:884-890.

Clark, D. L. \& G. W. Uetz. 1992. Morph-independent mate selection in a dimorphic jumping spider: demonstration of movement bias in female choice using video-controlled courtship behavior. Animal Behaviour 43:247-254.

Clark, D.L. \& G.W. Uetz. 1993. Signal efficacy and the evolution of male dimorphism in the jumping spider, Maevia inclemens. Proceedings of the $\mathrm{Na}-$ tional Academy of Sciences USA 90:1195411957.

Cokl, A., J. Presern, M. Virant-Doberlet, G.J. Bagwell \& J.G. Millar. 2004. Vibratory signals of the harlequin bug and their transmission through plants. Physiological Entomology 29:372-380.

Cokl, A., M. Zorovic, A. Zunic \& M. Virant-Doberlet. 2005. Tuning of host plants with vibratory songs of Nezara viridula L (Heteroptera: Pentatomidae). Journal of Experimental Biology 208: 1481-1488.

Crane, J. 1949. Comparative biology of salticid spiders at Rancho Grande, Venezuela. Part IV: an analysis of display. Zoologica 34:159-214.

Cutler, B. 1988. Courtship Behavior in Habronattus captiosus (Araneae, Salticidae). Great Lakes Entomologist 21:129-131.

DeVoe, R.D. 1975. Ultraviolet and green recepetors in principle eyes of jumping spiders. Journal of General Physiology 66:193-207.

Eakin, R.M. \& J.L. Brandenburger. 1971. Fine structure of the eyes of jumping spiders. Journal of Ultrastructure Research 37:618-663.

Edwards, G.B. 1981. Sound production by courting males of Phidippus mystaceus (Araneae: Salticidae). Psyche 88:199-214.

Edwards, G.B. \& R.R. Jackson. 1994. The role of experience in the development of predatory behaviour in Phidippus regius, a jumping spider (Araneae, Salticidae) from Florida. New Zealand Journal of Zoology 21:269-277.

Elias, D.O., E.A. Hebets \& R.R. Hoy. 2006a. Female preference for complex/novel signals in a spider. Behavioral Ecology 17:765-771.

Elias, D.O., E.A. Hebets, R.R. Hoy \& A.C. Mason. 2005. Seismic signals are crucial for male mating success in a visual specialist jumping spider (Araneae: Salticidae). Animal Behaviour 69:931938.

Elias, D.O., B.R. Land, A.C. Mason \& R.R. Hoy. 2006b. Measuring and quantifying dynamic visual signals in jumping spiders. Journal of Comparative Physiology A: Neuroethology, Sensory, Neural, and Behavioral Physiology 192:785797.

Elias, D.O., N. Lee, E.A. Hebets \& A.C. Mason. 2006c. Seismic signal production in a wolf spider: parallel versus serial multi-component sig- 
nals. Journal of Experimental Biology 209: 1074-1084.

Elias, D.O., A.C. Mason \& R.R. Hoy. 2004. The effect of substrate on the efficacy of seismic courtship signal transmission in the jumping spider Habronattus dossenus (Araneae: Salticidae). Journal of Experimental Biology 207:41054110.

Elias, D.O., A.C. Mason, W.P. Maddison \& R.R. Hoy. 2003. Seismic signals in a courting male jumping spider (Araneae: Salticidae). Journal of Experimental Biology 206:4029-4039.

Forster, L. 1982a. Vision and prey-catching strategies in jumping spiders. American Scientist 70: $165-175$.

Forster, L. 1982b. Visual communication in jumping spiders (Salticidae). Pp. 161-212. In Spider Communication: Mechanisms and Ecological Significance (P.N. Witt \& J.S. Rovner, eds.). Princeton University Press, Princeton, New Jersey.

Gerhardt, H.C. \& F. Huber. 2002. Acoustic Communication in Insects and Anurans: Common Problems and Diverse Solutions. University of Chicago Press, Chicago, Illinois. 531 pp.

Griswold, C.E. 1987. A revision of the jumping spider genus Habronattus F.O. P.-Cambridge (Araneae: Salticidae) with phenetic and cladistic analyses. University of California Publications in Entomology 107:1-344.

Gwynne, D.T. \& I.R. Dadour. 1985. A new mechanism of sound production by courting male jumping spiders (Araneae: Salticidae, Saitis michaelseni Simon). Zoological Society of London 207:35-42.

Harland, D.P. \& R.R. Jackson. 2000. Cues by which Portia fimbriata, an araneophagic jumping spider, distinguishes jumping-spider prey from other prey. Journal of Experimental Biology 203: 3485-3494.

Harland, D.P. \& R.R. Jackson. 2001. Prey classification by Portia fimbriata, a salticid spider that specializes at preying on other salticids: species that elicit cryptic stalking. Journal of Zoology 255:445-460.

Harland, D.P. \& R.R. Jackson. 2002. Influence of cues from the anterior medial eyes of virtual prey on Portia fimbriata, an araneophagic jumping spider. Journal of Experimental Biology 205: 1861-1868.

Harland, D.P., R.R. Jackson \& A.M. Macnab. 1999. Distances at which jumping spiders (Araneae: Salticidae) distinguish between prey and conspecific rivals. Journal of Zoology 247:357-364.

Hebets, E.A. \& W.P. Maddison. 2005. Xenophilic mating preferences among populations of the jumping spider Habronattus pugillis Griswold. Behavioral Ecology 16:981-988.

Hebets, E.A. \& D.R. Papaj. 2005. Complex signal function: developing a framework of testable hypotheses. Behavioral Ecology and Sociobiology 57:197-214.

Hill, D.E. 1979. Orientation by jumping spiders of the genus Phiddipus (Araneae: Salticidae) during the pursuit of prey. Behavioral Ecology and Sociobiology 5:301-322.

Hoefler, C.D. \& E.M. Jakob. 2006. Jumping spiders in space: movement patterns, nest site fidelity and the use of beacons. Animal Behaviour 71: 109-116.

Holland, B. \& W.R. Rice. 1998. Perspective: Chaseaway sexual selection: antagonistic seduction versus resistance. Evolution 52:1-7.

Honey, R.C. \& G. Hall. 1989. Attenuation of latent inhibition after compound pre-exposure: associative and perceptual explanations. Quarterly Journal of Experimental Psychology 41B:335-368.

Jackson, R.R. 1977. Courtship versatility in the jumping spider, Phidippus johnsoni (Araneae: Salticidae). Animal Behaviour 25:953-957.

Jackson, R.R. 1982. The behavior of communicating in jumping spiders (Salticidae). Pp. 213-247. In Spider Communication: Mechanisms and Ecological Significance (P.N. Witt \& J.S. Rovner, eds.). Princeton University Press, Princeton, New Jersey.

Jackson, R.R., X.J. Nelson \& G.O. Sune. 2005. A spider that feeds indirectly on vertebrate blood by choosing female mosquitoes as prey. Proceedings of the National Academy of Sciences USA 102:15155-15160.

Jackson, R.R. \& S.D. Pollard. 1996. Predatory behavior of jumping spiders. Annual Review of Entomology 41:287-308.

Kotiaho, J.S., R.V. Alatalo, J. Mappes, M.G. Nielsen, S. Parri \& A. Rivero. 1998. Energetic costs of size and sexual signalling in a wolf spider. Proceedings of the Royal Society of London B: Biological Sciences 265:2203-2209.

Krebs, J.R. \& D.E. Kroodsma. 1980. Repertoires and geographical variation in bird song. Advances in the Study of Behavior 11:143-177.

Land, M.F. 1969a. Movements of retinae of jumping spiders (Salticidae: Dendryphantinae) in response to visual stimuli. Journal of Experimental Biology 51:471-493.

Land, M.F. 1969b. Structure of retinae of principal eyes of jumping spiders (Salticidae: Dendryphantinae) in relation to visual optics. Journal of Experimental Biology 51:443-470.

Land, M.F. 1985. The morphology and optics of spider eyes. Pp. 53-78. In Neurobiology of Arachnids (F.G. Barth, ed.). Springer-Verlag, New York.

Land, M.F. \& D.-E. Nilsson. 2002. Animal Eyes. Oxford University Press, New York. 221 pp.

Li, D. \& M.L.M. Lim. 2005. Ultraviolet cues affect 
the foraging behaviour of jumping spiders. Animal Behaviour 70:771-776.

Maddison, W. \& M. Hedin. 2003. Phylogeny of $\mathrm{Ha}$ bronattus jumping spiders (Araneae: Salticidae), with consideration of genital and courtship evolution. Systematic Entomology 28:1-21.

Maddison, W. \& M. McMahon. 2000. Divergence and reticulation among montane populations of a jumping spider (Habronattus pugillis Griswold). Systematic Biology 49:400-421.

Maddison, W.P. \& G.E. Stratton. 1988a. A common method of sound production by courting male jumping spiders (Araneae, Salticidae). Journal of Arachnology 16:267-269.

Maddison, W.P. \& G.E. Stratton. 1988b. Sound production and associated morphology in male jumping spiders of the Habronattus agilis species group (Araneae, Salticidae). Journal of Arachnology 16:199-211.

Magal, C., M. Scholler, J. Tautz \& J. Casas. 2000. The role of leaf structure in vibration propagation. Journal of the Acoustical Society of America 108:2412-2418.

Masta, S.E. 2000. Phylogeography of the jumping spider Habronattus pugillis (Araneae: Salticidae): recent vicariance of sky island populations? Evolution 54:1699-1711.

Masta, S.E. \& W.P. Maddison. 2002. Sexual selection driving diversification in jumping spiders. Proceedings of the National Academy of Sciences USA 99:4442-4447.

Michelsen, A. 1978. Sound reception in different environments. Pp. 345-373. In Sensory Ecology: Review and Perspectives. (M.A. Ali, ed.). Plenum Press, New York.

Michelsen, A., F. Fink, M. Gogala \& D. Traue. 1982. Plants as transmission channels for insect vibrational songs. Behavioral Ecology and Sociobiology 11:269-281.

Michelsen, A. \& O.N. Larsen. 1983. Strategies for acoustic communication in complex environments. Pp. 321-331. In Neuroethology and Behavioral Physiology (F. Huber \& H. Markl, eds.). Springer-Verlag, New York.

Nakamura, T. \& S. Yamashita. 2000. Learning and discrimination of colored papers in jumping spiders (Araneae, Salticidae). Journal of Comparative Physiology A: Neuroethology, Sensory, Neural, and Behavioral Physiology 186:897901.

Nelson, X.J. \& R.R. Jackson. 2006. Compound mimicry and trading predators by the males of sexually dimorphic Batesian mimics. Proceedings of the Royal Society B-Biological Sciences 273:367-372.

Nelson, X.J., R.R. Jackson \& G. Sune. 2005. Use of Anopheles specific prey capture behavior by the small juveniles of Evarcha culicivora, a mos- quito-eating jumping spider. Journal of Arachnology 33:541-548.

Noordam, A.P. 2002. Abdominal percussion and ventral scutum in male Euophrys frontalis (Araneae: Salticidae). Entomologische Berichten, Amsterdam 62:17-19.

Parri, S., R.V. Alatalo, J.S. Kotiaho, J. Mappes \& A. Rivero. 2002. Sexual selection in the wolf spider Hygrolycosa rubrofasciata: female preference for drum duration and pulse rate. Behavioral Ecology 13:615-621.

Partan, S.R. \& P. Marler. 1999. Communication goes multimodal. Science 283:1272-1273.

Partan, S.R. \& P. Marler. 2005. Issues in the classification of multimodal communication signals. American Naturalist 166:231-245.

Peckham, G.W. \& E.G. Peckham. 1889. Observations on sexual selection in spiders of the family Attidae. Occasional Papers of the Wisconsin Natural History Society 1:3-60.

Peckham, G.W. \& E.G. Peckham. 1890. Additional observations on sexual selection in spiders of the family Attidae, with some remarks on Mr. Wallace's theory of sexual ornamentation. Occasional Papers of the Wisconsin Natural History Society $1: 117-151$.

Richman, D.B. 1982. Epigamic display in jumping spiders (Araneae, Salticidae) and its use in systematics. Journal of Arachnology 10:47-67.

Römer, H. 1998. The sensory ecology of acoustic communication in insects. Pp. 63-97. In Comparative Hearing: Insects (R. R. Hoy, A. N. Popper R. R. Fay, eds.). Springer-Verlag, New York.

Rowe, C. 1999. Receiver psychology and the evolution of multicomponent signals. Animal Behaviour 58:921-931.

Su, K.F.Y. \& D. Li. 2006. Female-biased predation risk and its differential effect on the male and female courtship behaviour of jumping spiders. Animal Behaviour 71:531-537.

Tarsitano, M.S. \& R.R. Jackson. 1992. Influence of prey movement on the performance of simple detours by jumping spiders. Behaviour 123:106120

Tarsitano, M.S. \& R.R. Jackson. 1994. Jumping spiders make predatory detours requiring movement away from prey. Behaviour 131:65-73.

Tarsitano, M.S. \& R.R. Jackson. 1997. Araneophagic jumping spiders discriminate between detour routes that do and do not lead to prey. Animal Behaviour 53:257-266.

Taylor, P.W., O. Hasson \& D.L. Clark. 2000. Body postures and patterns as amplifiers of physical condition. Proceedings of the Royal Society of London Series B-Biological Sciences 267:917922.

Taylor, P.W., O. Hasson \& D.L. Clark. 2001. Initiation and resolution of jumping spider contests: roles for size, proximity, and early detection of 
rivals. Behavioral Ecology and Sociobiology 50: 403-413.

Uetz, G.W. \& J.A. Roberts. 2002. Multisensory cues and multimodal communication in spiders: Insights form video/audio playback studies. Brain Behavior and Evolution 59:222-230.

Warshall, P. 1995. The Madrean sky island archipelago: a planetary overview. Pp. 6-18. In Biodiversity and Management of the Madrean Archipelago: the Sky Islands of the Southwestern United States and Northwestern Mexico (L.F.
DeBano, P.F. Ffolliott, A. Ortega-Rubio, G.J. Gottfried, R.H. Hamre \& C.B. Edminster, eds.). Rocky Mountain Forest and Range Experiment Station, Forest Service, U.S. Department of Agriculture, Fort Collins, Colorado.

Williams, D.S. \& P. McIntyre. 1980. The principal eyes of a jumping spider have a telephoto component. Nature 288:578-580.

Manuscript received 13 October 2005, revised 16 October 2006. 